\title{
Chikungunya-Dengue Co-Infection: Reports of Two Cases from Bangladesh
}

\author{
MA RAHIM $^{\mathrm{a}}$, S ZAMAN $^{\mathrm{b}}$, KN UDDIN $^{\mathrm{c}}$
}

\begin{abstract}
Summary:
Chikungunya and dengue are the two most rapidly spreading mosquito-borne viral infections of global public health concern. Dengue is endemic in Bangladesh and here chikungunya is anemerging infection. Because of the spacio-temporal relationship between chikungunya virus and dengue virus, their co-existence and concurrent outbreaks are not unlikely. Here, we report two cases of chikungunya-dengue co-infections occurring among young
\end{abstract}

\section{Introduction:}

Chikungunya virus, dengue virus and their common vectors, Aedes spp. of mosquitos are widely distributed throughout the world. ${ }^{1}$ Over the previous two decades, dengue has become established as an endemic disease in Bangladesh and an outbreak of chikungunya fever occurred in Dhaka, the capital of Bangladesh recently. ${ }^{2}$ In spite of widespreaddistribution of chikungunya virus, dengue virus and their vectors, co-infections by both the viruses are not that much common and such coinfection has only recently been reported from Bangladesh. ${ }^{1,3,4}$ We report two cases of chikungunyadengue co-infection occurring among young Bangladeshi patients. Such co-infections are predicted to be increased in coming years in Bangladesh. ${ }^{5}$

\section{Case Reports:}

Case 1

A 19-year-old male presented with a 3-day history of fever, headache and generalized bodyache. He had

a. Muhammad Abdur Rahim, Assistant Professor, Nephrology, Bangladesh Institute of Research and Rehabilitation for Diabetes, Endocrine and Metabolic Disorders (BIRDEM) General Hospital, Dhaka, Bangladesh.

b. Shahana Zaman, Junior Consultant, Cardiology, National Institute of Cardiovascular Diseases (NICVD), Dhaka, Bangladesh.

c. Khwaja Nazim Uddin, Professor, Internal Medicine, Bangladesh Institute of Research and Rehabilitation for Diabetes, Endocrine and Metabolic Disorders (BIRDEM) General Hospital, Dhaka, Bangladesh.

Address of Correspondence: Muhammad Abdur Rahim, Assistant Professor, Nephrology, BIRDEM General Hospital, Dhaka, Bangladesh. Email:muradrahim23@yahoo.com,Cell: 01741009000

Received: 9 November, 2017

Accepted: 23 August, 2018
Bangladeshi patients. Such co-infectionsneed special attention because pain management of chikungunyamay have adverse implications on patients with concurrent dengue infection.

Key words: Bangladesh, chikungunya, co-infection, dengue, sequential infection.

(J Bangladesh Coll Phys Surg 2019; 37: 86-88)

DOI: https://doi.org/10.3329/jbcps.v37i2.40566

suffered a 5-day long febrile illness 2 weeks earlier. At that time, he had pain involving the feet, ankles and lower back. His fever responded to paracetamol but joint pain persisted even after the disappearance of fever.

He was febrile (temp $102^{0} \mathrm{~F}$ ), tachycardic (pulse 104/ min) and had a normal blood pressure (BP) (130/80 $\mathrm{mm} \mathrm{Hg}$ ). His haemoglobin was $12.8 \mathrm{~g} / \mathrm{dL}$, total and differential white cell counts and platelets were normal (TC 6,500/cmm, neutrophils 74\%, lymphocytes $16 \%$, platelets $1,85,000 / \mathrm{cmm})$. Erythrocyte sedimentation rate (ESR) was $13 \mathrm{~mm}$ in $1^{\text {st }}$ hour. Dengue nonstructural protein 1 (NS 1) [done by immunochromatographic test (ICT) by using commercially available kits manufactered by Humasis Co. Ltd., Republic of Korea] and anti-chikungunya immunoglobulin M (IgM) (done by ICT for chikungunyaIgM/IgG by using commercially available kits manufactured by SD BIOSENSOR, Republic of Korea) were positive.

He was diagnosed as a case of chikungunya-dengue coinfection. He was onparacetamol and became afebrile on day 4after fever onset but developed generalized maculopapular rash and pruritus that responded to fexofenadine. Because of persistent low back pain even after 3 months fromthe first onset of fever, he was put on sulphasalazine, though there was no radiological evidence of sacroilitis and his human leukocyte antigen (HLA)B27 report is awaiting.

\section{Case 2}

A 45-year-old male presented with high grade continued fever for 3 days. He had generalized aches and pains and two episodes of vomiting on day of consultation. 


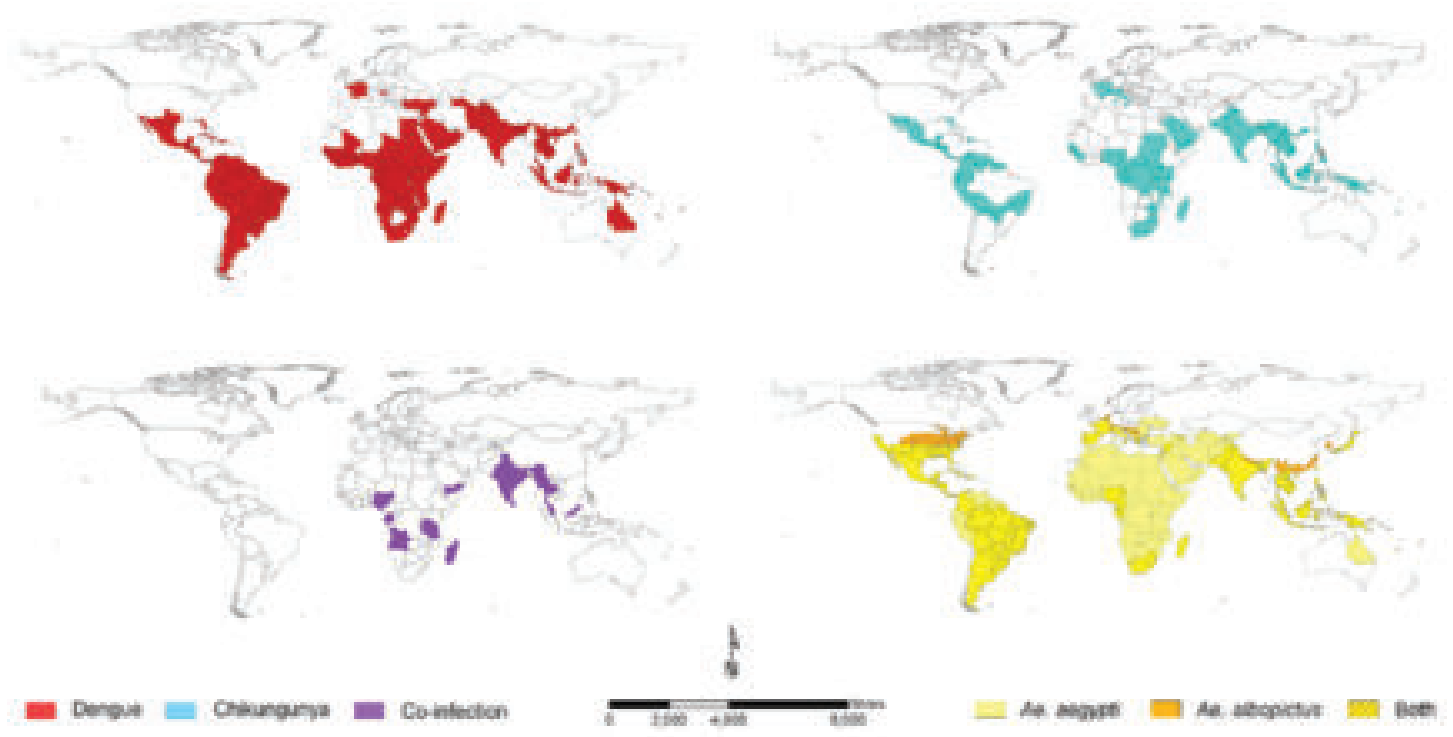

Fig.-1: The global distributions of endemic/epidemic dengue (top left) and chikungunya (top right) and reports of co-infection (bottom left) as well as the principal vectors of both arboviruses, Aedesaegypti and Aedesalbopictus (bottom right) [Adopted from Furuya-Kanamoriet al. BMC Infectious Diseases 2016;16:188]

Three weeks back, he had suffered a febrile illness of 4 days duration. On day 3 of his first febrile illness, he developed generalized maculopapular rash along with pruritus. He took paracetamol and fexofenadine as per advice of local pharmacist.

Physical examination at our center revealed that, the patient had fever $\left(103^{\circ} \mathrm{F}\right)$, dehydration, tachycardia $(100 / \mathrm{min})$ and low BP $(100 / 70 \mathrm{~mm} \mathrm{Hg})$ without any postural drop.He had a normal haemogram (haemoglobin $11.3 \mathrm{~g} / \mathrm{dL}$, total white cells $7,300 / \mathrm{cmm}$, platelets $2,10,000 / \mathrm{cmm})$ with raised ESR $(45 \mathrm{~mm}$ in $1^{\text {st }}$ hour). NS 1 for dengue (ICT) and antichikungunyaIgM(ICT) were positive.

He was treated with paracetamol, antiemetics and intravenous normal saline on $1^{\text {st }}$ day of admission. He was discharged after 2 days in afebrile state.

\section{Discussion:}

Chikungunya and dengue are fast spreading infections and increasing numbers of international travels have largely contributed to this spread. Furuya-Kanamori L, et al in 2016 reported that among the 98 countries where both chikungunya and dengue were documented, only 13 countries (Figure 1) had chikungunya-dengue co-infections including Angola, Gabon, India,
Madagascar, Malaysia, Myanmar, Nigeria, Saint Martin, Singapore, Sri Lanka, Tanzania, Thailand and Yemen. ${ }^{1,6}$ Such co-infections have also been reported from Bangladesh. ${ }^{3,4}$ As both dengue virus and chikungunya virus are transmitted by Aedes spp. of mosquitos, co-infection or sequential infection by both are possible. Simultaneous presenceof both the viruses have been demonstrated within the gut of same mosquito. ${ }^{7}$

Chikungunya and dengue are spacio-temporally

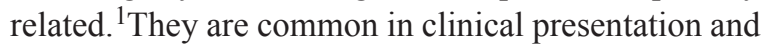
initial blood tests. Dengue NS 1 may detect dengue infection sufficiently early in disease course, real time reverse transcriptase polymerase chain reactions (RTPCR) can identify chikungunya and dengue up to 5 days since fever onset, RT-PCR and serology should be done in 5-7 days and IgM against chikungunya and dengue appear in blood at the end first week or beginning of second week of fever onset and persist for weeks to months. While paracetamolremains as the mainstay of treatment forchikungunya and dengue viral infections during acute febrile phase, arthritis of chikungunya may require non-steroidal anti-inflammatory drugs (NSAIDS) which may increase the risk for haemorrhagic manifestation of dengue. So, during an outbreak, it is important to exclude dengue first rather than to establish the diagnosis of chikungunya fever. ${ }^{2}$ 
Does co-infection by chikungunyavirus and dengue virus adversely affect each other and the host? Different studies did not find worse patient outcome except one, where case fatalities occurred among elderly patients. ${ }^{1,8-10}$

\section{Conclusion:}

As chikungunya is an emerging viral infection in Bangladesh with variable clinical presetation ${ }^{2}$, we emphasize that physicians should be aware of possible co-existence of chikungunya and dengue infections in coming years in appropriate clinical scenarios and during clinical management emphasis should be given to exclude dengue and care should be taken for to not use or minimize the use of NSAIDs in acute undifferentiated febrile illness.

\section{References:}

1. Furuya-Kanamori L, Liang S, Milinovich G, Magalhaes RJS, Clements ACA, Hu W, et al. Co-distribution and co-infection of chikungunya and dengue viruses. BMC Infectious Diseases 2016; $16: 84$.

2. Rahim MA, Uddin KN. Chikungunya: an emerging viral infection with varied clinical presentations in Bangladesh: Reports of seven cases. BMC Res Notes 2017;10:410.

3. Haque HF, Rahim MA, Mahiuddin N, Amin MG, Afroz F, Afroze SR, et al. Dengue-Chikungunya Co-Infection: A Case Report from 2017-Chikungunya Outbreak in Dhaka, Bangladesh. BIRDEM Med J 2018; 8(1): 72-74.
4. Rahim MA, Zaman S, Sultana N, Islam A, Uddin KN. Chikungunya-dengue co-infection during pregnancy requiring preterm Caesarean section: first case report from Bangladesh. Trop Doc 2017 (First PublishedDec 13, 2017). DOI: 10.1177/ 0049475517747431

5. Rahim MA, Uddin KN. Chikungunya-dengue co-infection: the upcoming double trouble! Bangladesh Crit Care J 2017;5(2):75-76.

6. Furuya-Kanamori L, Liang S, Milinovich G, Magalhaes RJS, Clements ACA, Hu W, et al. Erratum to: Co-distribution and coinfection of chikungunya and dengue viruses. BMC Infectious Diseases 2016; 16:188.

7. Le Coupanec A, Tchankouo-Nguetcheu S, Roux P, Khun H, Huerre M, Morales-Vargas R, et al. Co-Infection of Mosquitoes with Chikungunya and Dengue Viruses Reveals Modulation of the Replication of Both Viruses in Midguts and Salivary Glands of Aedesaegypti Mosquitoes. Int J MolSci 2017; 18:1708.

8. Taraphdar D, Sarkar A, Mukhopadhyay BB, Chatterjee S. A comparative study of clinical features between monotypic and dual infection cases with Chikungunya virus and dengue virus in West Bengal, India. Am J Trop Med Hyg 2012;86:720-23.

9. Omarjee R, Prat CM, Flusin O, Boucau S, Tenebray B, Merle O, et al. Importance of case definition to monitor ongoing outbreak of chikungunya virus on a background of actively circulating dengue virus, St Martin, December 2013 to January 2014. Euro Surveill 2014; 19(13). pii: 20753.

10. Chahar HS, Bharaj P, Dar L, Guleria R, Kabra SK, Broor S. Coinfections with chikungunya virus and dengue virus in Delhi, India. Emerg Infect Dis 2009; 15:1077-80. 